\title{
The Factors Influencing the Efficacy of Incidental Vocabulary Acquisition in English Reading*
}

\author{
Hui Liang \\ School of Foreign Languages \\ Jilin Institute of Chemical Technology \\ Jilin, China
}

\begin{abstract}
Incidental vocabulary acquisition refers to learning vocabulary without the intention to learn; it is an accidental cognitive activity when the Learners' attention focuses on the other things. The paper finds that the topics and the new word density of the reading materials can affect the incidental vocabulary acquisition by an empirical study. The purpose of the paper is to rich the theory of second language acquisition by discussing the factors influencing incidental vocabulary acquisition; meanwhile it aims to play a guiding role in the English vocabulary teaching.
\end{abstract}

Keywords-English reading; incidental vocabulary acquisition; factors

\section{INTRODUCTION}

Vocabulary is an indispensable part of language and is especially important for language learners. There are two main ways of vocabulary learning: intentional vocabulary learning and incidental vocabulary learning. Some domestic and foreign research experts and scholars have studied incidental vocabulary acquisition from different aspects. They believe learners do not deliberately acquire vocabulary during the learning process. In the words of Wode (1999:245), incidental vocabulary acquisition has been defined as "Language learning as a by-product of language used by the teacher or anybody else in the classroom, without the linguistic structure itself being the focus of attention or the target of teaching maneuvers". There are a lot of factors influencing incidental vocabulary acquisition, such as the topics of the reading materials, the psychological factors of learners, the new word density in reading passages and different learning strategies. This paper aims to explore the related factors influencing the incidental vocabulary acquisition from the two aspects: the topics and the new word density of the reading materials, and hopes to enrich the theoretical study of incidental vocabulary acquisition and also has some enlightenment on English vocabulary teaching.

*Fund project: Scientific Research Task of Higher Education Association of Jilin Province (JGJX2018D302):"“Dynamic Study on the Development of Formulaic Sequences and the Writing Ability of Foreign Language Learners"

Social and Science Task of Jilin Institute of Chemical Technology (2017059): "The Factors Influencing the Efficacy of Incidental Vocabulary Acquisition in English Reading"

\section{RESEARCH BACKGROUND}

Around the past 20 years or so, linguists and researchers have given great attention to vocabulary learning. Vocabulary has no longer played a role of discrimination in second language research or language teaching. Currently, vocabulary has been considered to be extremely important for any language acquisition. With the in-depth study of vocabulary by theoretical linguists, the importance of the vocabulary for English learners has also increased. A lot of researchers, teachers, task group designers, theorists and other people have been conducting the study of second language acquisition. A number of books and papers have been published, and various research reports have been made on this issue from the perspective of applied linguistics and psycholinguistics.

Recent researches have shown that learners need more vocabulary than before in current English learning. The conclusions drawn are: it is necessary to master $8,000-9,000$ word families for English learners to read materials smoothly; up to 5,000-7,000 word families may be required to communicate with people in daily life. In general, all of these learning tasks pose a significant challenge to vocabulary learners, and many or most learners are unable to meet such challenges.

The importance of reading for L2 learners' lexical development is generally acknowledged by researchers and theorists. The investigations have verified that learners incidentally gained a statistically significant amount of unfamiliar words while reading a text for global comprehension. However, an ongoing debate on the effectiveness of reading for L2 learners' vocabulary development has pinpointed pedagogical and methodological shortcomings of research to date. (Haynes, 1993; Hulstijn, 1996). Such a phenomenon is understandable considering that, L2 acquisition research that focused explicitly in incidental word gain through reading has failed to explain, describe, and account for factors that favorably affected the condition in which incidental word learning took place (Rott, 1999). But in order to increase the likelihood of incidental vocabulary acquisition during reading, research needs to determine the learner, word and text factors that have an impact on the acquisition process. 
This paper explores the factors influencing the incidental vocabulary acquisition in reading from the two perspectives: the topics and the new word density of the reading materials.

\section{METHODOLOGY}

\section{A. Research Questions}

This paper is mainly based on Krashen's "input hypothesis" theory (Krashen, 1984). Based on the theory and some empirical researches, the paper designs two reading tasks for the testers: firstly learners read some passages and then answer some questions and match the new words with their meanings. By analyzing the results of the two reading tasks, the following questions will be discussed:

- Whether the student can complete the incidental vocabulary acquisition by reading;

- Whether the topics of reading materials have an impact on students' incidental vocabulary acquisition;

- Whether the new word density of the reading materials has Influence on students' incidental vocabulary acquisition.

\section{B. Subjects of the Research}

The subjects of the research are 30 sophomores in English major from a college in Jilin. They come from two classes and have passed the TEM 4. Their vocabulary level is at a comparable level.

\section{Instrument}

The experiment focuses on the following two aspects: one is the influence of discourse topics on incidental vocabulary acquisition.

It verifies the influence of the discourse topics on students' semantic speculation of the new words. Whether Familiar topics and more background knowledge can stimulate students' learning motivation and promote the success of the semantic speculation.

Another aspect is the impact of new word density on incidental vocabulary acquisition

This part mainly verifies the influence of new word density on incidental vocabulary acquisition. For students, when the new word density is too high, they would be more likely to divert attention from reading. It will reduce cocontext support and lead to inefficient vocabulary learning. When the new word density is too low, learners can learn fewer new words from the reading. It also affects the incidental vocabulary acquisition. The specific research methods are as follows:

Based on Krashen's "input hypothesis" theory, the paper will design two reading tasks: the students read firstly and then answer some questions; connecting the given words with their English interpretations.

The topics of the reading materials selected in the first test are different. Students are required to read the passages with very familiar topics and unfamiliar topics on the premise that the new word density of the reading materials are about the same. The purpose of the test is to find out if the topics of the reading passages have some influences on students' lexical semantic speculation and whether familiar topics and more background knowledge can stimulate students' learning motivation and promote the success of semantic speculation.

The reading materials selected in the second test are mainly based on the vocabulary: the materials with lower new word density and the materials with higher new word density. This part mainly verifies the influence of new word density on incidental vocabulary acquisition. For students, when the new word density is too high, they would be more likely to divert attention from reading. It will reduce cocontext support and lead to inefficient vocabulary learning. When the vocabulary density is too low, learners can learn fewer new words from the reading. It also affects the incidental vocabulary acquisition.

\section{Procedures}

1) Reading materials: There are 4 reading passages, two of which is a group. The purpose of the experiment is to find out if the new word density and topics have some influences on incidental vocabulary acquisition. The first two articles: the title of the first one is "Critical Thinking" which is chosen form the English Extensive Reading 2 (Third Edition), this article has a total of 1638 words. Another article "The English Reserve and Politeness" is the first article in the English Extensive Reading 3 (Third Edition), it has 1,528 words. The total vocabulary of the two articles is similar and the new word density is with little difference. For students, critical thinking is an unfamiliar topic. Their background knowledge is very limited for such articles. The second article is about the conservation and courtesy of British people which are the contents of Survey of Brittan and America, so they have relatively more background knowledge of it.

Two passages in the second group: The first one is "A Mother's Place" which is the fifth passage in the English Extensive Reading 2 (Third Edition). This passage has a total of 1830 words. Another one is "Three Days to See" which is the eighth passage in the English Extensive Reading 3 (Third Edition), this article has a total of 1,834 words. The total vocabulary of the two articles is similar. The topics of the two passages are familiar to the students. The only difference is that the amount of new words in the second one is larger than the former. It is an important condition for testing whether new word density has an impact on the students' incidental vocabulary acquisition.

2) Reading comprehension: The reading comprehension test consists of multiple-choice questions and guessing vocabulary meaning. The single-choice question examines the comprehension of the original text. Each article has 10 questions, and each question has 4 options. Four of the 10 questions are related to explicit information in the original text, and the other 6 questions are related to implicit 
information. Vocabulary test involves 20 questions of connecting the new words with their interpretations. The score of each question is 1 point; the full marks are 30 points.

3) Results and analysis: After two sets of tests, it can be found that:

TABLE I. The Average SCORE OF THE StUdents IN THE FIRST GROUP

\begin{tabular}{|l|l|l|}
\hline \multicolumn{1}{|c|}{ Test Items } & $\begin{array}{l}\text { Single Choice } \\
\text { Questions (10) }\end{array}$ & $\begin{array}{c}\text { Guess the vocabulary } \\
\text { meaning (20) }\end{array}$ \\
\hline Critical Thinking & 5 & 11 \\
\hline $\begin{array}{l}\text { The English Reserve } \\
\text { and Politeness }\end{array}$ & 7 & 15 \\
\hline
\end{tabular}

TABLE II. The Average SCORE OF THE STUDENTS IN THE SECOND GROUP

\begin{tabular}{|l|l|l|}
\hline \multicolumn{1}{|c|}{ Test Items } & \multicolumn{1}{|c|}{$\begin{array}{c}\text { Single Choice } \\
\text { Questions (10) }\end{array}$} & $\begin{array}{c}\text { Guess the vocabulary } \\
\text { meaning (20) }\end{array}$ \\
\hline A Mother's Place & 8 & 16 \\
\hline Three Days to See & 6 & 12 \\
\hline
\end{tabular}

As can be seen in "Table I" and "Table II", the research results show that:

- Students can learn vocabulary through reading;

- Different discourse topics have some influence on students' incidental vocabulary acquisition. The reading tasks can stimulate the incidental vocabulary acquisition;

- The new word density directly affects the effect of incidental vocabulary acquisition. Excessive new words are not conducive to the students' incidental vocabulary acquisition.

\section{CONCLUSION}

The amount of the new words in reading materials has an impact on students' incidental vocabulary acquisition by analyzing the results of the experiment. The large amount of the new words is not conducive to students' understanding of the passages through context and hinders students from guessing their semantic meaning. In the process of reading, the new words are learned by guessing their meanings in cocontext. If a new word appears in the readers' familiar context again and again, it will be more beneficial to the acquisition of the word. This implicit approach of vocabulary acquisition is abundant in English reading, which has been fully confirmed by previous scientific research and the experiment.

In the process of incidental vocabulary acquisition, the learners certainly do not intentionally acquire the vocabulary when they are reading or doing other meaningful language activities. It is an unintentional cognitive activity. Through the above experimental research, we found the relationship between vocabulary acquisition, the topics of reading materials and the new word density.

\section{A. The Influence of Discourse Factors on Incidental Vocabulary Acquisition}

Discourse factors mainly refer to the topics of discourse. It mainly refers to the theme of the reading materials. Previous research mainly involved the relationship between topics and the speculation of lexical semantic meaning and the relationship between topics and incidental vocabulary acquisition. After experimental research, it is found that reading materials that are familiar to learners are often easier to mobilize their background knowledge, that is, learners can construct a graphical framework related to the reading materials in their minds, which is more conducive to the speculation of the new words. If learners are familiar with the topic of the passages and have a thorough understanding of the background culture, they can speed up their understanding of the new words, acquire vocabulary more quickly and understand the meaning of the passages more comprehensively.

Context and topic are closely related. Context here mainly refers to the linguistic context, that is, the context of the new words. It has a big influence on the incidental vocabulary acquisition. The conclusion of the experimental research is that the contextual information has a positive impact on the incidental acquisition of vocabulary, that is, the linguistic context has an influence on the incidental vocabulary acquisition, while the linguistic context is also influenced by the topics, background knowledge, culture context and the new word density of the reading materials. They interact between each other. This experiment also found that if the students are more familiar with the topic, they connect linguistic context more smoothly, the correct rate of the questions is higher; on the contrary, if the students are not familiar with the topics of the reading materials, they speculate the linguistic context slowly or stagnantly and they would make more mistakes on some invisible questions.

\section{B. The Influence of the New Word Density on Incidental Vocabulary Acquisition}

New word density refers to the amount of new words in the passage. It is found that there is a significant relationship between the new word density and incidental vocabulary acquisition. Reading materials with too many new words often have a negative impact on students' comprehension and incidental vocabulary acquisition. It is difficult for students to understand every sentence in the process of reading comprehension. The general meaning of the word cannot be speculated by the context, thus affect the incidental vocabulary acquisition.

\section{Enlightenment on Teaching and Second Language Acquisition}

The results of the experiment give us some inspiration for vocabulary teaching and second language acquisition. Firstly, English teachers should be keen to explore new teaching methods and provide students with a solid foundation of vocabulary acquisition. In addition, teachers should encourage students to develop a good habit of reading outside the classroom and access reading materials on different topics. Secondly, teachers should recognize the 
importance of vocabulary acquisition and guide students to improve vocabulary by combining the intentional and incidental acquisition methods during reading. Thirdly, the teacher should know the word-base of the students and choose appropriate reading materials for them, it can help students develop reading interest and then improve students' incidental vocabulary acquisition.

\section{REFERENCES}

[1] Coady, J. \& Huckin, T. Second Language Vocabulary Acquisition.. Cambridge: Cambridge University Press, 1997, 1-2.

[2] Schmitt, N. Review Article: Instructed Second Language Vocabulary Learning. Language Learning Research, 2008, 12(3):329.

[3] Krashen, S. Writing: Research, Theory and Applications. Oxford: Pergammon, 1984.

[4] Krashen, S. The Input Hypothesis: Issues and Implications. London: Longman, 1985.

[5] Krashen, S. Principles and Practice in Second Language Acquisition. Great Britain: Prentice Hall International (UK) Ltd., 1987.J. Clerk Maxwell, A Treatise on Electricity and Magnetism, 3rd ed., vol. 2. Oxford: Clarendon, 1892, pp.68-73.

[6] Krashen, S. We Acquire Vocabulary and Spelling by Reading: Additional Evidence for the Input Hypothesis. Modern Language Journal, 1989, 73(4).

[7] Schmidt, R. The Role of Consciousness in Second Language Learning. Applied Linguistics, 1990.

[8] Haynes, M. Patterns and perils of guessing in second language reading. Norwood, New Jersey: Ablex, 1993.

[9] Hulstijn, J. Incidental vocabulary learning by advanced foreign language students: The influence of marginal glosses, dictionary use, and reoccurrence of unknown words. The Modern Language Journal, 80, 327-339.1996.

[10] Rott, S. The effect of exposure frequency on intermediate language learners, incidental vocabulary acquisition and retention through reading. Studies in second language acquisition, 21, 589-619. 1999.

[11] Wode,H. Incidental vocabulary acquisition in the foreign language classroom. Studies in second language acquisition, 21, 243-258. 1999. 